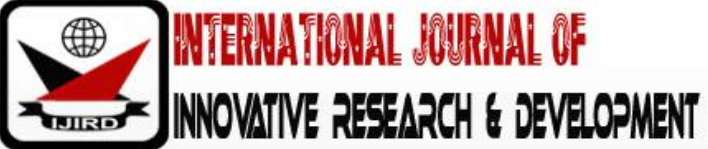

ISSN 2278 - 0211 (Online)

\section{Some Engineering Properties of Cashew Nut Related to the Design of Processing Equipment}

\author{
Gbadamosi Lateef \\ Principal Lecturer, Department of Agricultural and Bio-Environmental Engineering \\ Technology, Kwara State Polytechnic, Ilorin, Nigeria
}

\begin{abstract}
:
Some engineering properties of cashew-nut related to the design of processing equipment namely: size, sphericity, roundness, surface area, static coefficient of friction against different materials, angles of repose and specific heat capacity were studied. Major diameter, intermediate diameter and minor diameter for the Brazilian nut and local nut were $38 \mathrm{~mm}$ and $30.6 \mathrm{~mm}, 22.2 \mathrm{~mm}$ and $18.3 \mathrm{~mm}$ and $19 \mathrm{~mm}$ and $16.7 \mathrm{~mm}$ respectively. Values of 2.19 and 1.95 for the roundness for the two varieties respectively and values of 0.66 and 0.70 for the sphericity for the two varieties respectively. The nuts have highest coefficients of friction for the galvanized steel and lowest for glass for the Brazilian nut and local nuts. The specific heat capacity values were $3.014 \mathrm{j} / \mathrm{g}^{\circ} \mathrm{Cand} 4.93 \mathrm{j} / \mathrm{g}^{\circ} \mathrm{C}$ for the Brazilian and Local nut respectively.
\end{abstract}

Keywords: Engineering property, cashew nut, processing, equipment

\section{Introduction}

Cashew plant (Anacardium Occidentals) is an erect perennial shrub that is mostly found in the tropics and subtropical regions of the world. The major producing countries of cashew are Tanzania, Thailand, India, Mozambique, SriLanka, Nigeria, Senegal, Malawi, Malaysia, Indonesia and Angola (Addo et al., 2012). The fruits when ripen is edible when its nuts contain resin known as cashew nut shell liquid (CNSL). This shell liquid is mostly composed of anacardid acid which can treat tooth abscesses and its kernel when extracted contains oils which has medicinal values for the treatment of rashes in the body, it has been successfully applied to cure ringworms, cancerous ulcers, etc. cashew nuts is very nutritious with high amount of energy as it contains protein, vitamins and fibre, all of which contribute enormously to good health from its consumption. Other useful products made from cashew are jam, juices, syrup and beverages, (Winterhaler, 1991). Presently, the nut is manually cracked by using stones, mortar and pestle, or and other suitable device. This manual methods of cracking the nuts is tedious, energy sapping and grossly inadequate to meet the present demand of bye products of the nut. As the initial stage in developing a machine for processing the nuts, the physical properties needed to be studied. Physical properties of cashew nut and kernel like other cereals, fruits and vegetables are needed for the design of processing equipment. Also, it was reported that the study of physical properties plays an important role in developing sensors to control machines and processes. It helps to detect quality differences during harvesting, handling and storage (Addo et al., 2012).

Various types of cleaning, grading and separation equipment are designed on the basis of the physical properties of crops (Teye and Abano, 2012). According to (Esref and Halil, 2007), the knowledge of physical properties constitutes an important and essential engineering data in the design of machine, storage structures and processing. The objective of the study is to determine some of the engineering properties of the cashew nuts namely: size, sphericity, roundness, volume, surface area, static coefficient of friction, angle of repose and specific heat capacity. Sphericity is defined as the ratio of the surface area of a sphere which has the same volume as that of the solid, to the surface area of the solid or it express the shape characteristics of a solid material relative to a sphere. Roundness of a solid is a measure of shape and is defined as the ratio of the largest projected area of an object in its natural rest position to the area of the smallest circumscribing circle.

The sphericity and roundness of cashew nut and kernel can be calculated by the following expressions (Mohsenin, 1980). Sphericity $=\frac{d_{i}}{d_{c}}$.......

Roundness $=\frac{A_{p}}{A_{c}}$

Where $d_{c}$ and $A_{c}$ represents the diameter and area of the smallest circumscribing circle respectively, $d_{i}$ denotes the diameter of the largest inscribing circle and $A_{p}$ represents the projected area of the grain. Sphericity can also be determined from the expression as follow;

Sphericity $=\frac{(a b c)^{1 / 3}}{c}$. 
Where $a, b, c$, are major, intermediate and minor diameter respectively.

The surface areas (s) of the nut were determined from the expression.

Surface area $(\mathrm{s})=\pi D_{p}^{2}$

Where,

$\mathrm{S}=$ surface area $\left(\mathrm{cm}^{2}\right)$

$D_{p}^{2}=$ Geometric mean diameter of the nut $\left(\mathrm{cm}^{2}\right)$

Mohsenin, (1980)

The volume $(\mathrm{V})$ of the nuts were computed from the expression

$$
\text { density }=\frac{\text { mass }}{\text { volume }} \text {. }
$$

\section{Materials and Methods}

Some quantity of cashew seeds, Brazilian and local varieties were sourced from the ministry of Agriculture, Ilorin, Kwara State. One hundred seeds for each variety were randomly selected from collected quantity. Measurements of dimensions on the three mutually perpendicular axes were made namely: major, intermediate and minor diameters. These dimensions were measured with vernier calipers. Sphericity of the nut were determined from the equation (2). Each nut was placed in its natural resting position on a sheet of graph paper. A sharp thin pencil was used to carefully trace the edges of the seed. The projected area and the diameters of circles, inscribing and circumscribing the projected areas were measured (Oje and Ugor, 1991).

The surface area was computed using the relationship given by (Mohsenin, 1980) using the equation (5). The mass of each cashew nut was measured with a sensitive analytical balance of $0.01 \mathrm{gm}$ accuracy. The static coefficient of friction for the seeds was determined with respect to three structural materials, namely: plywood, galvanizedsteel and glass.

A topless and bottomless box of dimensions $150 \times 100 \times 40 \mathrm{~mm}$ was filled with cashew seeds and placed on an adjustable tilting surface. One end of the surface with the box resting on it was raised gradually with screw device until the box just started to slide down.

The angle of repose of the nut was determined by filling a cylindrical pipe of height $40 \mathrm{~cm}$ and internal diameter of $13.4 \mathrm{~cm}$. The pipe was slowly raised above the floor so that the whole materials fall and formed a conical heap. The angle of repose was calculated from the height and base diameter of the piled material using the expression.

$$
=\tan ^{-1} \frac{2 H}{D}
$$

An adiabatic drop calorimeter was used to determine the specific heat capacity of the nuts by the method of mixture (Oje and Ugor, 1991). Water of known weight and temperature was poured into a calorimeter containing nuts. At equilibrium, the final temperature was noted, specific heat capacity (Cs) was calculated by the expression.

$C s=\frac{C W M C(T W i-T t)}{M 3(T l i-T t)}$

Where,

$\mathrm{Cs} \quad=\quad$ Specific heat capacity of the nut $\mathrm{J} / \mathrm{g}^{0} \mathrm{C}$

$\mathrm{Cw}=$ Specific heat capacity of water $/ \mathrm{g}^{0} \mathrm{C}$

$\mathrm{Mw}=$ Mass of water $(\mathrm{gm})$

Twi $=$ Initial water temperature, ${ }^{0} \mathrm{C}$

$\mathrm{Tt}=\quad$ Final temperature of mixture ${ }^{0} \mathrm{C}$

$\mathrm{Tsi}=$ Initial; seed temperature, ${ }^{0} \mathrm{C}$

\section{Results and Discussions}

\subsection{Size}

Table 1 presents a summary of the result for all the parameters measured. Table 1 shows the range of size of the two varieties cashew nut of between $16.1 \mathrm{~mm}$ and $22.2 \mathrm{~mm}$. The major diameter, intermediate diameter and minor diameter of Brazilian nut are greater than those of local nut. The different in size is important in the selection of sieve or screen size in the design of grinding equipment and in the design of shelling machine for the cashew nuts.

\subsection{Sphericity}

The local cashew nut was found to be most spherical in shape with mean sphericity value of 0.70 . The sphericity different between the two varieties 0.04, when compared with standard value obtained by (Oje and Ugor, 1991). It shows that the nut would rather roll than slide. This property could assist in the design of hopper of the processing equipment, design of drying and storage equipment.

\subsection{Roundness}

The mean roundness value of Brazilian nut is greater than that of the local nut, which are 2.19 and 1.95 respective. The difference in roundness value of Brazilian and local nut is 0.24 . This value indicate that the nut can roll when compare with standard value obtained by Sign (1996). The property can be useful in determining the proper shape of the metering unit and the best feeding orientation of the nuts in the design of planter for the nut. 


\subsection{Coefficient of Sliding Friction}

The coefficient of sliding friction is highest for galvanized steel for the local nut of 0.82 followed by that of plywood of 0.76 for Brazilian nut and least values of 0.71 for the two varieties for Glass. This property is important in the determination of the steepness of the storage container, hopper or any other loading or unloading devices if any of these is to be used as the vertical load on the wall of the storage container is determined by friction coefficient.

\subsection{Angle of Repose}

The mean angle of repose is $21^{\circ}$ for Brazilian and $21.2^{\circ}$ for the local nut. This property is essential in the determination of the relative size of length (diameter) and height of an appropriate storage structure for the nuts.

\subsection{Specific Heat Capacity}

The mean specific heat capacity for the Brazilian nut and the local nut are $3.014 \mathrm{j} / \mathrm{g}^{0} \mathrm{c}$ and $4.93 \mathrm{j} / \mathrm{g}^{0} \mathrm{c}$ respectively. The variations in the surface area of the two varieties of nuts explain why the specific heat capacity of local nut was highest. This property can be used to determine the amount of heat required in the processing of the nut.

\section{Conclusions}

The following conclusions were drawn from the investigations conducted on some of the engineering properties of cashew nut.

- The sizes of the two varieties of cashew nut examined were measured along the major, intermediate and minor axes. These sizes vary widely from $16.7 \mathrm{~mm}$ and $38 \mathrm{~mm}$

- The shape of the nuts was described by its roundness and sphericity. The minimum sphericity value is 0.66 and maximum sphericity value is 0.70 and the minimum roundness value is 1.95 and the maximum roundness is 2.19 .

- The coefficient of sliding friction was highest on steel and least on glass for the two varieties of cashew nut

- The specific heat capacity depends on the surface area of the cashew nut. The more the surface are the less the specific capacity

\section{References}

i. Addo, A, Bart-plange, A, Mohammed-Kamil A,P. and Teye, E (2012) some physical and mechanical properties of cashew nut and kernel grown in Ghana. Internal journal of science and nature, vol3 (2) $406-415$.

ii. Esrif, I and Halil, U. (2007) moisture - dependent physical properties of white speckled red kidney bean grains. Journal of food Engineering, 82, $209-216$

iii. Oje, K. and Ugor, E.C (1991) some physical properties of oil beans seed. Journal of Agriculture Engineering Research 50:305 - 313

iv. Teye, E, and Abano, E, E, (2012) physical properties of two varieties of sweet potato grown in the coastal Savannah zone of Ghana, International Journal of science and nature 3(1) 105 - 109

v. Mohsenin, N.N (1980) physical properties of plant and animal materials. Gordon and breach science publishers, New York Pp51, - 87

vi. Singh, K.K and Goswami, T. K. (1996) physical properties of cumin seed. Journal of Agricultural Engineering Research. 64, $93-98$

vii. Winterhaler, H.H (1991) physical properties related to drying twenty food grains American Society of Agricultural Engineering, $80-353$.

\section{Appendix}

\begin{tabular}{|c|c|c|c|}
\hline \multirow[t]{2}{*}{ Property } & \multirow{2}{*}{$\begin{array}{c}\text { Number of } \\
\text { Observation }\end{array}$} & \multicolumn{2}{|c|}{ Mean Value and Spread } \\
\hline & & Brazilian Nut size $(\mathrm{cm})$ & Local Nut \\
\hline Major diameter & 100 & $3.80 \pm 0.185$ & $3.06 \pm 0.150$ \\
\hline Intermediate diameter & 100 & $2.22 \pm 0.152$ & $1.83 \pm 0.115$ \\
\hline Minor diameter & 100 & $1.90 \pm 0.165$ & $1.67 \pm 0.125$ \\
\hline Surface area $\left(\mathrm{cm}^{2}\right)$ & 30 & $21.91+2.357$ & $15.05 \pm 1.60$ \\
\hline Mass (gm) & 30 & $9.90 \pm 1.416$ & $5.37 \pm 0.69$ \\
\hline Roundness & 100 & $2.19 \pm 0.370$ & $1.95 \pm 0.407$ \\
\hline Sphericity & 100 & $0.66 \pm 0.023$ & $0.070 \pm 0.020$ \\
\hline Static coefficient of friction & 5 & $0.768 \pm 0.066$ & $0.756 \pm 0.080$ \\
\hline Plywood & 5 & $0.780 \pm 0.024$ & $0.822 \pm 0.031$ \\
\hline $\begin{array}{ll}\text { (b) } & \text { Galvanized steel } \\
\text { (c) } & \text { Glass }\end{array}$ & 5 & $0.71 \pm 0.02$ & $0.71 \pm 0.02$ \\
\hline Angle of repose (degrees) & 5 & $21 \pm 0.65$ & $21.20 \pm 1.09$ \\
\hline Specific heat capacity $\mathrm{j} / \mathrm{g}^{0} \mathrm{C}$ & 25 & $3.014 \pm 0.62$ & $4.93 \pm 0.64$ \\
\hline
\end{tabular}

Table 1: Some Physical Properties of the Two Varieties of Cashew Nut (Brazilian Nut and Local Nut) 